\title{
BMJ Open Global health competencies in UK postgraduate medical training: a scoping review and curricular content analysis
}

\author{
Nader Al-Shakarchi, ${ }^{1}$ Lucy Obolensky, ${ }^{2}$ Sarah Walpole, ${ }^{3}$ Harry Hemingway, ${ }^{\oplus 4,5}$ \\ Amitava Banerjee ${ }^{4,5}$
}

To cite: Al-Shakarchi N, Obolensky L, Walpole S, et al. Global health competencies in UK postgraduate medical training: a scoping review and curricular content analysis. BMJ Open 2019;9:e027577. doi:10.1136/ bmjopen-2018-027577

- Prepublication history and additional material for this paper are available online. To view these files, please visit the journal online (http://dx.doi. org/10.1136/bmjopen-2018027577).

Received 29 October 2018 Revised 31 May 2019 Accepted 17 July 2019

Check for updates

C Author(s) (or their employer(s)) 2019. Re-use permitted under CC BY-NC. No commercial re-use. See rights and permissions. Published by BMJ.

${ }^{1}$ Medical School, University College London, London, UK ${ }^{2}$ Faculty of Medicine and Dentistry, Plymouth University Peninsula Medical School,

Plymouth, UK

${ }^{3}$ Hull York Medical School, Hull, UK

${ }^{4}$ Institute of Health Informatics, University College London, London, UK

${ }^{5}$ Health Data Research UK, London, UK

Correspondence to

Dr Amitava Banerjee; ami.banerjee@ucl.ac.uk

\section{ABSTRACT}

Objective To assess global health (GH) training in all postgraduate medical education in the UK.

Design Mixed methodology: scoping review and curricular content analysis using two GH competency frameworks.

Setting and participants A scoping review (until December 2017) was used to develop a framework of GH competencies for doctors. National postgraduate medical training curricula were analysed against this and a prior framework for $\mathrm{GH}$ competencies. The number of core competencies addressed and/or appearing in each programme was recorded.

Outcomes The scoping review identified eight relevant publications. A 16-competency framework was developed and, with a prior 5-competency framework, used to analyse each of 71 postgraduate medical curricula. Curricula were examined by a team of researchers and relevant learning outcomes were coded as one of the 5 or 16 core competencies. The number of core competencies in each programme was recorded.

Results Using the 5-competency and 16-competency frameworks, 23 and 20 , respectively, out of 71 programmes contained no global health competencies, most notably the Foundation Programme (equivalent to internship), a compulsory programme for UK medical graduates. Of a possible 16 competencies, the mean number across all 71 programmes was $1.73(95 \% \mathrm{Cl}$ 1.42 to 2.04) and the highest number were in paediatrics and infectious diseases, each with five competencies. Of the 16 core competencies, global burden of disease and socioeconomic determinants of health were the two most cited with 47 and 35 citations, respectively. 8/16 competencies were not cited in any curriculum. Conclusions Equity of care and the challenges of practising in an increasingly globalised world necessitate $\mathrm{GH}$ competencies for all doctors. Across the whole of postgraduate training, the majority of UK doctors are receiving minimal or no training in $\mathrm{GH}$. Our GH competency framework can be used to map and plan integration across postgraduate programmes.

\section{INTRODUCTION}

The rationale for global health $(\mathrm{GH})$ education in medical training has been well established for well over a century since tropical medicine courses began in Edinburgh and London in the 1890s. ${ }^{1}$ Policy

\section{Strengths and limitations of this study}

In the first comprehensive study across all 71 programmes in UK postgraduate medical training using mixed methods (scoping literature review, iterative development of a current, generalisable global health (GH) competency framework, and curricular content analysis), we demonstrated that $\mathrm{GH}$ is significantly under-represented in postgraduate clinical training curricula.

- GH education and the extent to which relevant competencies are included in the curriculum vary significantly between specialties.

- Only GH competencies for training physicians were studied. Not all doctors have national curricula (eg, consultants and doctors not in training such as associate specialists and staff grade clinicians) in the UK, and it is therefore not possible to assess GH competencies in their ongoing training and development. We did not consider undergraduate medical training or training of other health professionals.

- Our study was restricted to the UK.

recommendations and published literature suggest that health professionals, including doctors, should be prepared for increasing globalisation, changing migration patterns across and within countries, and emerging epidemics. ${ }^{2-4}$ In an era of Sustainable Development Goals, awareness of equity and human rights issues has never been more important. ${ }^{5}$ Although differences across healthcare systems and the required training for health professionals between high-income and low-income countries are often emphasised, there is also convergence in some of the challenges facing all countries (eg, informatics and data science ${ }^{78}$ ).

A Lancet Commission Report has emphasised a common global strategy for postgraduate healthcare professional education beyond the boundaries of countries and professions, ${ }^{2}$ but in order to train all doctors in $\mathrm{GH}$, the definition and the scope for education and training need to be clarified. 
GH emphasises "transnational health issues, determinants, and solutions; involves many disciplines within and beyond the health sciences... and is a synthesis of population-based prevention with individual-level clinical care". ${ }^{9}$ GH has been described through five metaphors: foreign policy ("to exert political influence"), security ("to protect the population"), charity ("to fight poverty"), investment ("maximising economic development") and public health ("to decrease worldwide burden of disease"), ${ }^{10}$ and through three principles: health for all (equity: "aimed at reaching all people in the world"), health in all (coherence: "in all policies including those influencing social and environmental determinants") and health by all (participation: "influenced and improved by a broad scope of actors"). ${ }^{11}$

Unfortunately, there is "a mismatch between present professional competencies and the requirements of an increasingly interdependent world". ${ }^{2}$ In the UK, despite policy and strategy at professional and governmental level, ${ }^{12-14}$ a 'lack of global health awareness in postgraduate curricula' persists. ${ }^{15}$ The establishment of GH education has taken place in undergraduate training with intercalated and master's degrees in $\mathrm{GH}$ and international health being introduced in the last three decades, but integration of GH in postgraduate medical training has lagged. ${ }^{416}$ The discourse and progress with GH in postgraduate curricula is advancing at a greater pace in North America, ${ }^{17} 18$ but internationally, postgraduate GH training is not currently a priority. ${ }^{19} 20$ Doctors need to be prepared for the greatest challenges facing health systems and societies on national or international levels, but no country, to date, has universal GH training for its doctors.

The UK has seen a growth in postgraduate courses for $\mathrm{GH}$, but the content of curricula did not reflect recommended competencies. ${ }^{21}$ Understanding the degree to which GH is currently present in postgraduate curricula is an important step in establishing appropriate GH components in postgraduate medical training, for which a tiered qualification system has been proposed. ${ }^{16}$ Specific postgraduate global health competencies have recently been proposed.$^{22}$ A recent review examined 11 postgraduate medical and surgical curricula in the UK, ${ }^{15}$ but the entire pathway of postgraduate medical training (which includes 65 specialty curricula, 5 core curricula and the Foundation Programme; online supplementary appendix 1 ; web figure 1) has not been considered.

A current and comprehensive perspective of $\mathrm{GH}$ content within UK postgraduate medical training is required to inform design and implement of GH training across all specialties in the UK and could be informative to other countries. We therefore (1) identified current consensus standards in $\mathrm{GH}$ training, (2) developed a new framework of GH competencies, (3) compared GH content in all postgraduate medical specialties against these standard competencies and (4) suggested ways to move towards global health competencies for all UK postgraduate doctors.

\section{METHODS}

We conducted a mixed-methodology study with three components (scoping review, framework development and curricula content analysis) to iteratively develop proposed universal GH standards for postgraduate medical training in the UK.

\section{Scoping review}

A scoping review was conducted to identify articles relating to global health in postgraduate medical education. We searched PubMed and Google Scholar between 1 January 1998 and 31 December 2017 with no language restrictions applied, using the search strategy (online supplementary appendix 2$)$ :

(( ( global health OR international health) AND (training OR education OR competencies OR competency OR syllabus OR syllabi OR curricula OR curriculum) AND (postgraduate OR doctor OR clinician OR physician) NOT (undergraduate OR medical student OR nursing OR pharmacy OR allied health professional))) AND ("1998/01/01"(PDat): "2017/12/31"(PDat)))

Documents were eligible for inclusion if they described postgraduate GH competencies that specified training doctors within their target population (ie, curricula relating exclusively to nursing, pharmacy and allied health professionals, as well as undergraduate medical training were excluded). Exclusion criteria also included article duplication or documents which examined only part of the GH curriculum, rather than its overall content.

Articles were screened in three stages, by title then abstract and finally by full review. Data extraction included author details, year of publication, country of study, type of curricula (eg, academic and/or clinical), study population (competency target population), place of intended dissemination (university, hospital environments etc), methodology and specific GH competencies. EndNote $\mathrm{X} 8$ was used to identify duplicates during the initial stages of the scoping review. At the final stage, reference lists of included documents were used to identify additional eligible documents.

\section{Framework development}

The competencies identified from the scoping review were examined by all authors. By consensus, the framework most applicable and most contemporary to the UK postgraduate medical education context was identified. In addition, a new comprehensive list of core competencies for GH in postgraduate medical curricula was developed by identifying common competencies across all publications identified by the scoping review, and by agreement of all authors.

\section{Curricular content analysis}

In August 2017, relevant documents for the whole curriculum relating to all components of UK postgraduate medical education were retrieved (figure 1). Relevant documents were identified as those containing one or more of the search terms 'Syllabus', 'Curriculum' 


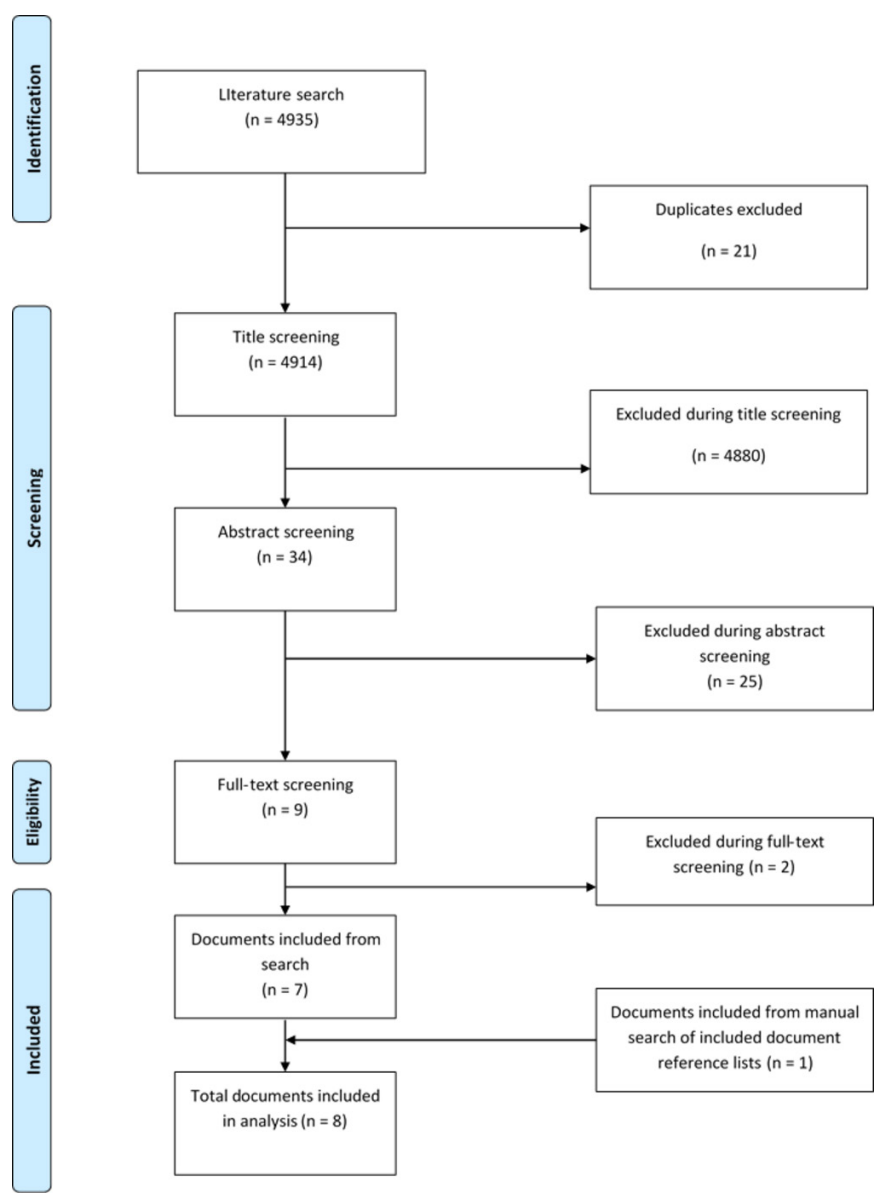

Figure 1 Flow diagram of included studies in scoping review.

or 'Core Competencies'. The curriculum for the Foundation Programme was obtained from the UK Foundation Programme Office website, ${ }^{23}$ while the curricula for core and specialty training were accessed from the list of approved specialties on the General Medical Council website, ${ }^{24}$ except for ophthalmology. ${ }^{25}$ The ophthalmology curriculum was accessed from the Royal College of Ophthalmologists website. Subspecialty curricula were included despite not being a compulsory part of specialty training. The full list of curricula analysed is in the online supplementary appendix.

Two researchers (NA and $\mathrm{AB}$ ) independently reviewed 71 curricula (online supplementary appendix 1), identifying the competencies contained within them that matched to one of the core GH competencies (in both the new and the existing frameworks). The advanced search function on Adobe Reader XI, with the search terms outlined in the appendix, were used to map GH competencies to curricula. The number of core competencies achieved by each curriculum was recorded as well as the number of valid citations. A citation was defined as clear evidence that knowledge, application or understanding of the core GH competency in question was either a requirement of the curriculum or it was subject to assessment. Moreover, explicit mention of a potential international or global perspective was also required. For competencies with multiple components such as 'Human Rights and Ethics', a citation would still be valid if it only mentioned one component, for example, 'Human Rights'. Citations were deemed invalid if they were found to be irrelevant, a duplicate or a generic competency unrelated to GH. In instances of disagreement, consensus was reached by discussion between $\mathrm{NA}$ and $\mathrm{AB}$.

The main outcome measure for assessing GH content in curricula was the number of core competencies addressed rather than citation frequency (figure 2 and web figure 2) since it was felt that further credit should not be given for having more than one learning outcome relating to the same core competency. Citation frequency was only used in the comparison of different core competencies (figure 3). Core competencies identified within subspecialty curricula were added to their attached specialty unless they were found to be duplicates.

Curricular analysis by faculty groupings and Royal Colleges was also performed to identify variation both within and between different organisations offering postgraduate training, for example, cardiology, gastroenterology and neurology were studied individually and also among all medical specialties overseen by the Joint Royal College of Physicians Training Board (JRCPTB). The mean probability of a newly qualified doctor having two or fewer GH competencies during their entire postgraduate training, regardless of specialty, was estimated using observed frequencies of core GH competencies across different specialties and stages of training.

\section{Ethics}

No ethical approval was required since all data used for this study were freely available online (from the last 5 years, and if the content was less recent, then the relevant specialist organisation was contacted to check the availability of a more up-to-date version), and no patient data were used.

\section{Patient and public involvement}

Patients and the public were not directly involved in this study.

\section{RESULTS}

\section{Scoping review}

From 4935 references yielded by our search, 8 publications were eligible for inclusion (table 1) with one paper found from a manual search of reference lists. ${ }^{15}$ The year of publication ranged from 2011 to 2017, with three publications from the UK and USA, and two from Canada. All documents described clinically related competencies except one paper which used a combination of clinical and academic competencies. All competencies had a target audience of training clinicians with two papers aimed at particular specialties, which were still included due to their universally applicable competencies. Methodologies consisted of literature review exclusively $(n=2)$, a combination of literature review and Delphi consultation 

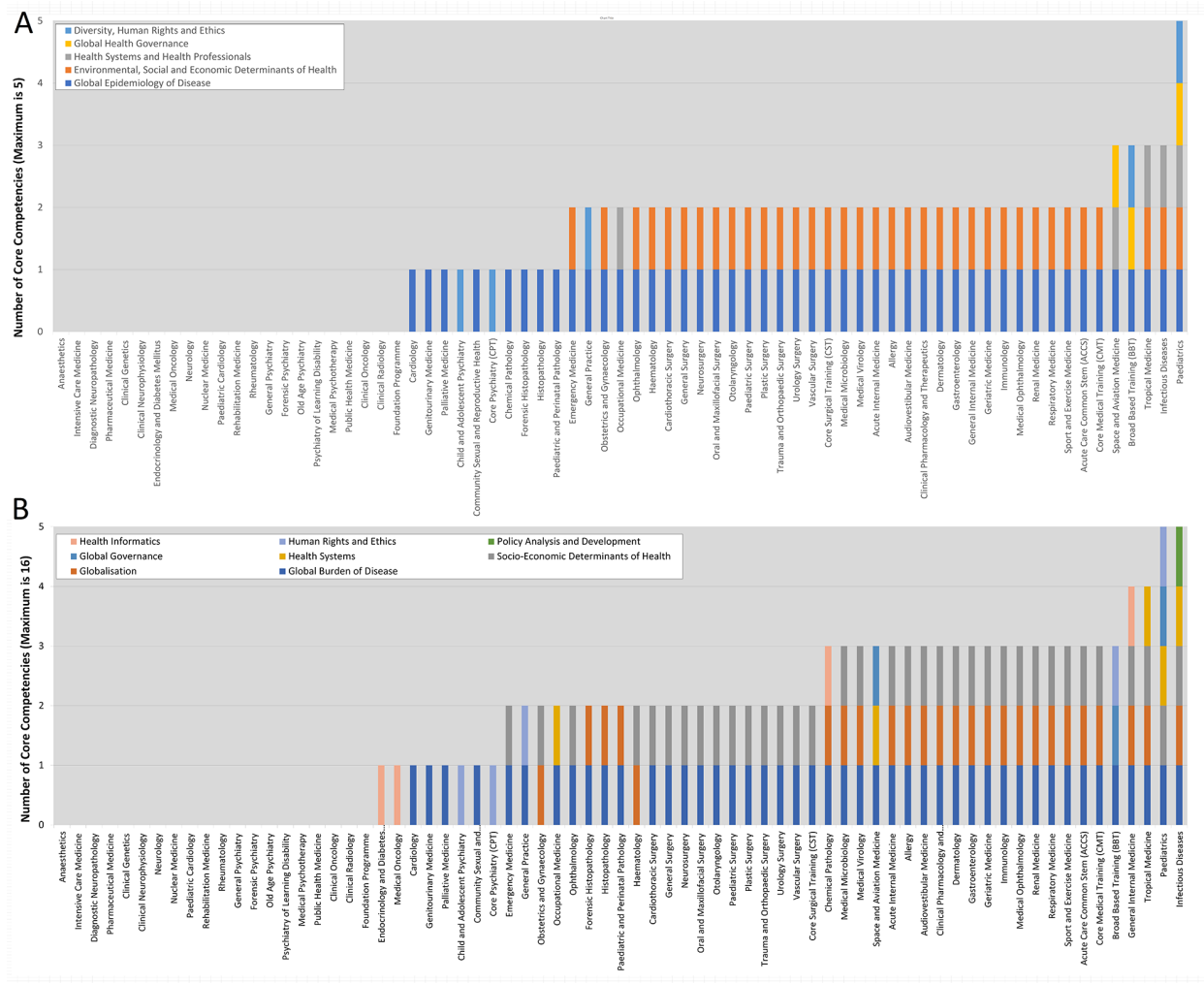

Figure 2 Number of core competencies achieved by postgraduate curricula.

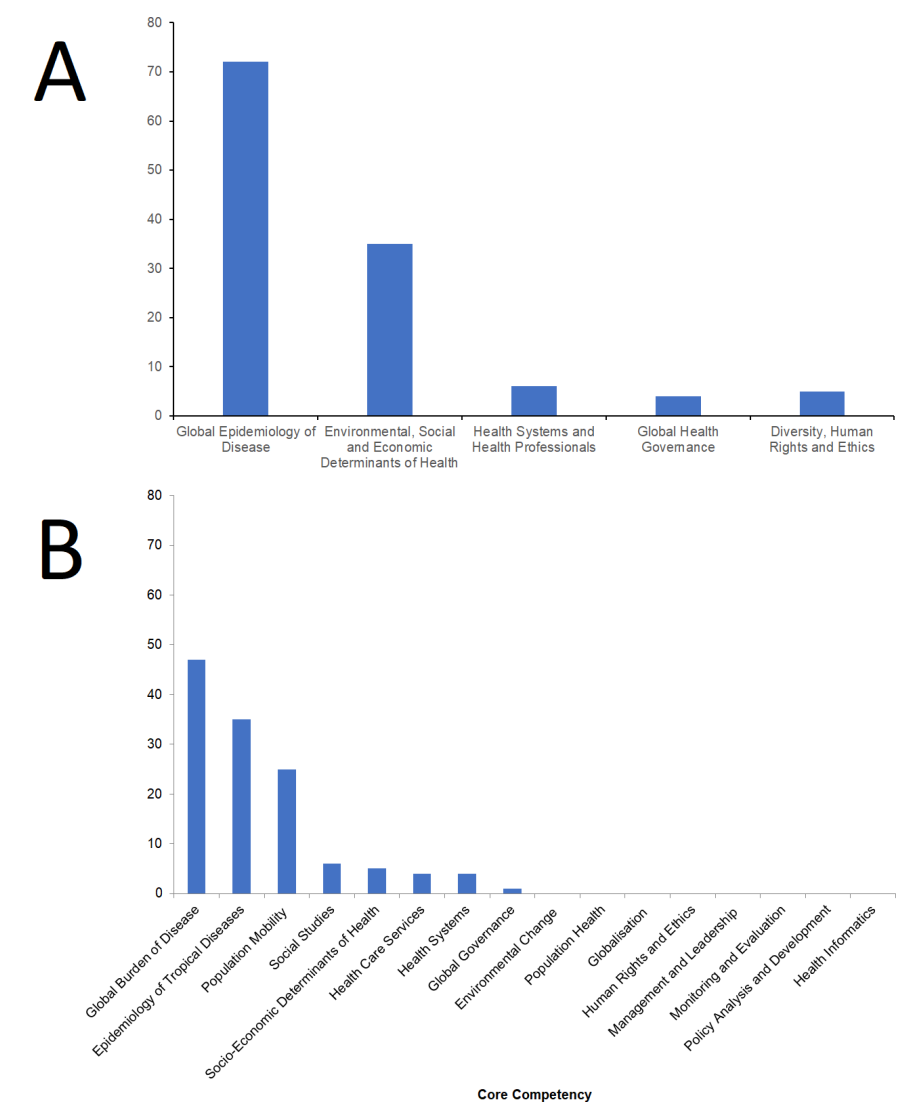

Figure 3 (A, B) Citations by global health competency. or reflection $(\mathrm{n}=2)$, Delphi consultation or meetings exclusively $(n=2)$, and surveys or interviews $(n=2)$.

\section{Framework development}

The Walpole et al framework (2016) ${ }^{22}$ was identified as the most relevant list of competencies for the UK postgraduate context, which had been developed through a rigorous process involving over 250 stakeholders (table 2A). A broader core competency framework $(n=16)$ was also developed, informed by the scoping review ${ }^{13} 15-18$ (table 2B), to include "the widest possible array of GH competencies" ${ }^{14}$ for UK medical practice. Similar identified GH competencies were coupled with others to produce a single core competency with a broader heading. For example, 'management' and 'leadership' were paired together to form the 'management and leadership' core competency. Other core competencies such as 'epidemiology of tropical diseases' were formed by narrowing down competencies such as 'global epidemiology' since aspects of this are shared with 'global burden of disease'. 'Health Informatics' (HI) was included, reflecting the increasingly important role of eHealth within GH and the recent adoption of a digital health resolution by WHO. ${ }^{26}$ 'Inter-organisational information exchange and data governance' from the International Medical Informatics Association recommendations, applicable to every country, was used to identify eHealth within curricula. ${ }^{27}$ Furthermore, the introductory skill level of the domain 
Table 1 Scoping review for global health competencies for postgraduate doctors

\begin{tabular}{|c|c|c|c|c|}
\hline $\begin{array}{l}\text { First author/journal } \\
\text { (reference) }\end{array}$ & $\begin{array}{l}\text { Year of } \\
\text { publication }\end{array}$ & Country & Methodology & Global health competencies \\
\hline $\begin{array}{l}\text { Arya. Can Fam } \\
\text { Physician }^{34}\end{array}$ & 2017 & Canada & $\begin{array}{l}\text { Literature review } \\
\text { and expert } \\
\text { consensus }\end{array}$ & $\begin{array}{l}\text { 1. Global burden of disease } \\
\text { 2. Socioeconomic determinants of health } \\
\text { 3. Health system planning }\end{array}$ \\
\hline $\begin{array}{l}\text { Wroe. J Grad Med } \\
\text { Educ }^{35}\end{array}$ & 2017 & USA & $\begin{array}{l}\text { Interview of trainees } \\
\text { and assessment } \\
\text { using standardised } \\
\text { tool }\end{array}$ & $\begin{array}{l}\text { 1. Patient care } \\
\text { 2. Mentoring, teaching and management } \\
\text { 3. Systems-based practice } \\
\text { 4. Interpersonal and cross-cultural communication } \\
\text { 5. Professionalism and self-care }\end{array}$ \\
\hline $\begin{array}{l}\text { Dawe. Can Med } \\
\text { Educ } J^{36}\end{array}$ & 2017 & Canada & $\begin{array}{l}\text { Literature review } \\
\text { and Delphi survey }\end{array}$ & $\begin{array}{l}\text { 1. Social determinants of health } \\
\text { 2. Principles and ethics of global health } \\
\text { 3. Cultural humility and competency } \\
\text { 4. Health systems, policy and advocacy for change } \\
\text { 5. Community engagement }\end{array}$ \\
\hline Walpole. Int Health ${ }^{22}$ & 2016 & UK & Delphi consultation & $\begin{array}{l}\text { 1. Global health governance } \\
\text { 2. Health systems and professionals } \\
\text { 3. Human rights and ethics, diversity } \\
\text { 4. Global epidemiology of disease } \\
\text { 5. Environmental, social and economic determinants } \\
\text { of health }\end{array}$ \\
\hline $\begin{array}{l}\text { Tupesis. Acad Emerg } \\
\text { Med }^{38}\end{array}$ & 2013 & USA & Expert consensus & $\begin{array}{l}\text { 1. Cultural competency } \\
\text { 2. Health equity and human rights } \\
\text { 3. Communication, leadership and evaluation } \\
\text { 4. Burden of disease } \\
\text { 5. Ethics and professionalism } \\
\text { 6. Healthcare systems and delivery models } \\
\text { 7. Social/political/economic awareness } \\
\text { 8. Health informatics }\end{array}$ \\
\hline $\begin{array}{l}\text { Hall. JRSM Short } \\
\operatorname{Rep}^{15}\end{array}$ & 2013 & UK & $\begin{array}{l}\text { Curricular content } \\
\text { analysis }\end{array}$ & $\begin{array}{l}\text { 1. Global burden of disease } \\
\text { 2. Socioeconomic and environmental determinants } \\
\text { 3. Health systems } \\
\text { 4. Global health governance } \\
\text { 5. Human rights and ethics } \\
\text { 6. Cultural diversity and health }\end{array}$ \\
\hline $\begin{array}{l}\text { Bjorklund. Am J Trop } \\
\text { Med Hyg }\end{array}$ & 2011 & USA & Survey of trainees & 1. Migrant health (population health and mobility) \\
\hline
\end{tabular}

also means that it can easily be modified and implemented into postgraduate training.

\section{Curricular content analysis}

The curricula for all 71 programmes were available and analysed using both the Walpole $(n=5)$ and the new $(n=16)$ frameworks. Figure 2 illustrates the number of core competencies by specialty. Across all curricula, there were 95 and 127 citations of $\mathrm{GH}$, with a mean number of GH competencies addressed of 1.34 (95\% CI 1.09 to 1.58 ) and 1.73 (95\% CI 1.42 to 2.04 ), respectively, for the Walpole and new frameworks.
Of the five core competencies in the Walpole framework, paediatrics addressed the highest number of 5. Twenty-three curricula had no mention of GH in their competencies, notably including the foundation programme, and 93\% (66/71) had two GH competencies or fewer. Four specialties had three out of five core $\mathrm{GH}$ competencies, including broad-based training, infectious diseases and tropical medicine. Looking only at the 65 specialty curricula, the mean number of competencies was 1.31 (95\% CI 1.05 to 1.57 ) (figure $2 \mathrm{~A}$ ).

Of the 16 core competencies in the new framework, paediatrics and infectious diseases were the curricula 
Table 2 Framework for competencies in global health in postgraduate medical curricula

(A) Global health competencies proposed by Walpole et $a^{22}(n=5)$

\begin{tabular}{ll}
\hline Global health competency & Description \\
\hline Global epidemiology of & Describe the distribution of health and disease globally
\end{tabular}

disease

Environmental, social and economic determinants of health

Understand the global nature of the environmental, social and economic determinants of health, including air and water quality, climate, culture, religion, gender, history and politics. Employ knowledge of these global factors to advocate for strategies that tackle health inequalities and improve health

Health systems and health professionals

Describe how your own health system is structured, governed and financed. Understand how your health system compares with other health systems across the globe and how this impacts on health outcomes. Describe how global factors and globalisation influence the functioning of health systems and the work of health professionals

Global health governance

Describe the roles of key actors in global health, including international organisations, the commercial sector and civil society. Understand how global funding mechanisms can influence the design and outcome of research strategies and policies, and how policies made at a global or national level can impact on health at a local level

Diversity, human rights and Respect the rights and equal value of all people without discrimination. Provide compassionate ethics and respectful care for all patients

\section{(B) Global health competencies synthesised from scoping review $(n=16)$}

\section{Global health competency Examples of learning outcomes/descriptors}

Global burden of disease $\quad$ Be aware of the distribution of health inequalities both nationally and internationally and the factors that contribute to this

Socioeconomic determinants - Be aware of the influence of economic and politic considerations (on a local and global of health scale) on individual and community health and how these may be influenced

Global governance

- Understand the broad role of WHO and its influence of UK medical practice

Health systems

- Outline the role of the UK's health protection agencies and other NHS and governmental organisations at local, national and international levels in the control of, and emergency planning for, outbreaks of infection

\begin{tabular}{|c|c|}
\hline Social studies & - Appreciate the differences in healthcare delivery within multiple cultural settings \\
\hline Population mobility & De aware of the impact of population migration and displacement on immigrant health \\
\hline $\begin{array}{l}\text { Healthcare and patient } \\
\text { services }\end{array}$ & $\begin{array}{l}\text { Be able to perform an adequate patient history and physical examinations in resource-poor } \\
\text { settings }\end{array}$ \\
\hline $\begin{array}{l}\text { Epidemiology of tropical } \\
\text { diseases }\end{array}$ & $\begin{array}{l}\text { Demonstrate an understanding of travel medicine and appreciate the key considerations } \\
\text { outlined by the Centers for Disease Control and Prevention ('the six l's') for patients } \\
\text { travelling to regions with known tropical disease }\end{array}$ \\
\hline Environmental change & - Demonstrate awareness of the effect of natural disasters on migrant health \\
\hline Population health & $\begin{array}{l}\text { Be aware of the major responses of populations to international outbreaks of infectious } \\
\text { disease }\end{array}$ \\
\hline Monitoring and evaluation & - Consider the role of systems thinking in managing international health issues \\
\hline Management and leadership & Engage with health organisations that have an international scope \\
\hline $\begin{array}{l}\text { Policy analysis and } \\
\text { development }\end{array}$ & - Demonstrate implementation of policy and directives applicable to local and global practice \\
\hline Human rights and ethics & $\begin{array}{l}\text { Demonstrate an understanding of human rights legislation (Human Rights Act and European } \\
\text { Convention of Human Rights) and its relevance to medical practice }\end{array}$ \\
\hline Globalisation & $\begin{array}{l}\text { Describe the impact of globalisation on health, major causes of global morbidity and } \\
\text { mortality, and effective and affordable interventions to reduce these }\end{array}$ \\
\hline Health informatics & $\begin{array}{l}\text { Appreciate methods and approaches to networking and shared care (eHealth, health } \\
\text { telematics applications and interorganisational information exchange) on a global scale }\end{array}$ \\
\hline
\end{tabular}

which addressed the highest number of 5 . Twenty curricula had no mention of $\mathrm{GH}$ in their competencies, again including the foundation programme, and more than two-thirds of all programmes had $\leq 2 \mathrm{GH}$ competencies. Nineteen specialties had 3 out of 16 core GH competencies, including the acute care common stem and 
core medical training. For specialty curricula, the mean number of competencies was 1.71 (95\% CI 1.39 to 2.02) (figure 2B).

Figure 3 demonstrates the number of citations of each of the 5 and $16 \mathrm{GH}$ competencies, respectively. For the Walpole framework, global epidemiology of disease and environmental, social and economic determinants of health were most frequently cited with 72 and 35 citations, respectively, across all curricula. Sixty-nine per cent of all programmes included competencies about global epidemiology of disease. Only nine curricula mentioned the remaining three competencies (figure $3 \mathrm{~A}$ ). For the new framework, global burden of disease, socioeconomic determinants of health and globalisation were the most frequently cited with 47,35 and 25 citations, respectively, across all curricula. Sixty-three per cent of all programmes required some understanding of the global burden of disease; however, fewer than half mentioned the remaining 15 competencies with $8 \mathrm{GH}$ competencies not being cited in any of the curricula (figure 3B).

Web figure 1 demonstrates the frequency of GH competencies throughout different parts of postgraduate training using the new framework. Although the Foundation Programme has no competencies, subsequent core training programmes incorporate between one and three competencies. Both run-through programmes, that is, those which take trainee directly from post-Foundation training through to Consultant status (see web figure 1, eg, Obstetrics and Gynaecology, Neurosurgery, Paediatrics, Chemical Pathology, Ophthalmology, Clinical Radiology, Histopathology and Public Health), and other specialty training programmes had between zero and five GH competencies. Assuming a newly trained doctor is equally likely to follow any specialty (ie, any of the training routes in web figure 1 , including general practice) in their postgraduate training, the probability that they will achieve two or more $\mathrm{GH}$ competencies during their entire training is $27.4 \%$. Moreover, since certain run-through programmes such as Clinical Radiology and Public Health have no GH competencies, a certain proportion of clinicians will achieve no competencies at all throughout their training.

Web figure 2 illustrates the curricular content analysis by faculty groupings and Royal Colleges for the new framework of competencies. Of the 15 Royal Colleges and faculty groupings examined, 4 contained none of the competencies and 7 had at least one specialty training programme that failed to mention a single GH competency. The 29 specialty training curricula offered by the JRCPTB demonstrated the greatest range in GH competencies (mean 2.03; range of $0-5$ ).

\section{DISCUSSION}

To our knowledge, this is the first review of GH across the full spectrum of postgraduate medical education in the UK, which includes 71 training programmes. There are three main findings. First, based on a scoping review, we identified an existing framework and developed a comprehensive and contemporary list of GH competencies applicable to postgraduate curricula in the UK. Second, we demonstrate that there is currently little GH coverage throughout UK postgraduate training (from the Foundation Programme to specialty training (figure 2)) and that approximately one in four physicians achieve two or fewer GH competencies during their entire postgraduate training (web figure 1). Third, we show that there is significant variation in included GH competencies, both in individual specialties and when specialties are considered in groups (web figure 2). For instance, the JRCPTB, which is responsible for 29 postgraduate medical specialties, offers seven programmes with no GH competencies, while its remaining 22 programmes contain at least one GH competency.

From the National Institute for Health Research Global Health initiatives to WHO, the need for critical awareness and skills in GH for every doctor is increasingly recognised. Modern-day clinicians are constantly faced with the challenges of living in an interconnected world and the health issues that globalisation poses to our population. However, our findings indicate a paucity of GH clinical competencies in current curricula both in terms of literature review and mapping of UK postgraduate specialties. The "mismatch between present professional competencies and the requirements of an increasingly interdependent world" ${ }^{27}$ is of concern for all clinicians, as GH adapts generic skills covered at a national level to manage the issues of a globalised world such as fluctuating migration patterns and emerging epidemics. To date, the development of GH education for health professionals has mainly been focused around undergraduate and MSc curricula for GH degrees/programmes. Such programmes have had some success at increasing GH competencies in small, self-selected cohorts within the body of postgraduate doctors. This $\mathrm{GH}$ training should now be translated into UK postgraduate medical training such that core competencies are achieved by all those completing training.

In a reproducible methodology, 16 competencies were identified during this study and interestingly, the low coverage of GH competencies was also confirmed when a shorter, established list of five competencies was used. Our list of GH competency domains builds on previous work and adds new domains relevant to current healthcare priorities, including health informatics. GH, like all areas of health science and practice, is dynamic and training must keep pace with the changing landscape. 'Big data' and health informatics are not just a priority for high-income settings but have great potential in low-income countries as well. ${ }^{8}$ If postgraduate training in $\mathrm{GH}$ does not incorporate knowledge of data management and analysis, then the 'digital divide' between high-income and low-income countries ${ }^{28}$ may be exacerbated by a 'digital health education' gap. Competencies in evidence-based medicine ${ }^{29}$ medical ethics ${ }^{30}$ and informatics ${ }^{31}$ have been successfully integrated into the training of all clinicians. 
Our framework aims to address the lack of GH coverage using a similar approach.

Infectious Diseases and Paediatrics curricula mapped to the highest number of competencies, perhaps in part due to the outlook of the clinicians in these specialties and their governing bodies, historic association between these specialties and 'tropical medicine', and the prominence of bodies such as the WHO and UNICEF. Although many specialties contain fewer competencies such as psychiatry, cardiology, oncology, and obstetrics and gynaecology curricula, the Global Burden of Disease study ${ }^{32}$ and other large-scale international studies have shown that diseases treated within these specialties account for the majority of morbidity and mortality in all countries. Therefore, the argument that GH training should favour certain specialties is not coherent.

There are a number of strengths to this study. First, as the study examined all 71 postgraduate curricula, a complete perspective of $\mathrm{GH}$ coverage throughout the current postgraduate training pathway could be formulated. Furthermore, the mixed-methodology design involving a scoping literature review and curricular content analysis allowed iterative development of a current, generalisable GH competency framework for all doctors, which can be elaborated on and validated in further studies. We also compared with an existing framework (Walpole et $a l$ ). The coding by two independent reviewers with agreement by consensus where there was any inconsistency was also a strength. Comparison of programmes between and within different institutions also enabled inconsistencies in GH content to be detected. There are several limitations. We did not consult educators and curriculum developers. We used citation frequency which did not take into account the depth or extent of each citation. Whether a competency is related to GH within curricula is subjective. The GH content in the training of other health professionals $^{33}$ was not included in this analysis and we did not consider continuing professional development post-completion of specialist training. The acceptability and feasibility of developing these domains into curricula was not investigated. The study was only conducted in the UK and is probably not generalisable to all other countries, that is, different countries may require a different set of competencies. The challenges in the integration of globally relevant themes into postgraduate training were not examined, including competition for space in the curriculum with other specialty-specific and universal competencies. We only considered curricular content and neither enaction nor implementation.

The curricular content analysis carried out in this study will provide an important foundation for ongoing work in determining the curricula that require more GH content and the competencies that require more attention for clinical training. A forthcoming next step is to interview curriculum developers and curriculum receivers (ie, trainees) in a Delphi technique to understand their view on the importance of $\mathrm{GH}$ competencies in their chosen specialty curriculum. In addition, the disparity in
GH between different institutions highlighted will help support the development of nationwide GH standards in physician training. Further validation of our GH competency framework would be informative, particularly in other countries. Local adaptation of our list of GH competencies is likely to be required due to the different environments and different specialties. Integration of GH into postgraduate medical training may initially focus on programmes that currently do not have any GH content. A cross-specialty approach may be more scaleable than each individual specialty finding its own solution.

\section{CONCLUSION}

This study has found many UK programmes lack global health content. Integrating global health competencies at an early stage of postgraduate training could help equip UK trainees with the necessary GH experience to address the challenges of practising in an increasingly globalised world.

Contributors The study was conceived by $\mathrm{AB}$. AB and NA designed data collection tools, monitored data collection, wrote the statistical analysis plan, carried out the analysis, collected data and produced the initial draft of the manuscript. $A B$ was guarantor. SW, $\mathrm{LO}$ and $\mathrm{HH}$ contributed to the design of the data collection tools and monitoring of data collection. All authors had full access to all data and can take responsibility for the integrity and accuracy of the data analysis. All authors contributed to revision of the manuscript and have accepted the final version.

Funding The authors have not declared a specific grant for this research from any funding agency in the public, commercial or not-for-profit sectors.

Competing interests None declared.

Patient consent for publication Not required.

Provenance and peer review Not commissioned; externally peer reviewed.

Data availability statement Data are available on reasonable request.

Open access This is an open access article distributed in accordance with the Creative Commons Attribution Non Commercial (CC BY-NC 4.0) license, which permits others to distribute, remix, adapt, build upon this work non-commercially, and license their derivative works on different terms, provided the original work is properly cited, appropriate credit is given, any changes made indicated, and the use is non-commercial. See: http://creativecommons.org/licenses/by-nc/4.0/.

\section{REFERENCES}

1. London School of Hygiene \& Tropical Medicine, 2017. Available: https://en.wikipedia.org/wiki/London_School_of_Hygiene_\%26_ Tropical Medicine

2. Frenk J, Chen L, Bhutta ZA, et al. Health professionals for a new century: transforming education to strengthen health systems in an interdependent world. Lancet 2010;376:1923-58.

3. Wagner K, Jones J. Caring for migrant patients in the UK: how the migrant health guide can help. Br J Gen Pract 2011;61:546-7.

4. Martineau F, Johnson O, Rowson M, et al. International health graduates-career path experience. Lancet 2012;379:2051-2.

5. Rasanathan K. 10 years after the Commission on Social Determinants of Health: social injustice is still killing on a grand scale. Lancet 2018;392:1176-7.

6. Kruk ME, Gage AD, Arsenault C, et al. High-quality health systems in the sustainable development goals era: time for a revolution. Lancet Glob Health 2018;6:e1196-252.

7. Whittaker M, Hodge N, Mares RE, et al. Preparing for the data revolution: identifying minimum health information competencies among the health workforce. Hum Resour Health 2015;13:17.

8. Quintana Y, C S. Chapter 1-Global Health Informatics-An Overview. In: HdF M, Massad E, Gutierrez MA, et al, eds. Global health informatics - how information technology can change our lives in a globalized world. Academic Press, 2017: 1-13.

9. Koplan JP, Bond TC, Merson MH, et al. Towards a common definition of global health. Lancet 2009;373:1993-5. 
10. Stuckler D, McKee M. Five metaphors about global-health policy. Lancet 2008;372:95-7.

11. Garay J, Harris L, J W. Global health: evolution of the definition, use and misuse of the term. Face a face 2013;12.

12. HM Government. Health is global: UK global health strategy 20082013, 2008.

13. Physicians. RCo. Building institutions through equitable partnerships in global health: a two day global health conference held at the Royal College of Physicians. 14-15 April 2011, 2011. Available: https://www.acmedsci.ac.uk/viewFile/53d79ed38b19a. pdf

14. Royal College of Obstetricians \& Gynaecologists. RCOG IO statement on health is global. A UK government strategy 2008-2013, 2008.

15. Hall J, Brown C, Pettigrew L, et al. Fit for the future? The place of global health in the UK's postgraduate medical training: a review. JRSM Short Rep 2013;4:19-8.

16. Brown C, Martineau F, Spry E, et al. Postgraduate training in global health: ensuring UK doctors can contribute to health in resourcepoor countries. Clin Med 2011;11:456-60.

17. Drain PK, Rhatigan JJ. Global health training should be structured, standardized, and universal. Acad Med 2014;89:530-1.

18. Drain PK, Primack A, Hunt DD, et al. Global health in medical education: a call for more training and opportunities. Acad Med 2007;82:226-30.

19. Mitchell RD, Jamieson JC, Parker J, et al. Global health training and postgraduate medical education in Australia: the case for greater integration. reply. Med J Aust 2013;199:102.

20. Pati S, Sinha R, Panda M, et al. Global health teaching in India: a curricular landscape. Front Public Health 2017;5.

21. Harmer A, Lee K, Petty N. Global health education in the United Kingdom: a review of university undergraduate and postgraduate programmes and courses. Public Health 2015;129:797-809.

22. Walpole SC, Shortall C, van Schalkwyk MC, et al. Time to go global: a consultation on global health competencies for postgraduate doctors. Int Health 2016;8:317-23.

23. UKFPO Curriculum \& e-portfolio, 2017. Available: http://www. foundationprogramme.nhs.uk/pages/resource-bank/curriculumeportfolio

24. GMC full list of approved curricula, 2017. Available: http://www.gmcuk.org/education/approved_curricula_systems.asp

25. Royal College of Ophthalmologists. Summary table for ophthalmic specialist training, 2017. Available: https://www.rcophth.ac.uk/ curriculum/ost/summary/
26. World Health Organization. eHealth at WHO, 2018. Available: http:// www.who.int/ehealth/about/en/

27. Mantas J, Ammenwerth E, Demiris G, et al. Recommendations of the International Medical Informatics Association (IMIA) on education in biomedical and health informatics. First revision. Methods Inf Med 2010;49:105-20.

28. Banerjee A. Bridging the global digital health divide for cardiovascular disease. Circ Cardiovasc Qual Outcomes 2017;10:e004297.

29. Albarqouni L, Hoffmann T, Straus S, et al. Core competencies in evidence-based practice for health professionals: consensus statement based on a systematic review and Delphi survey. JAMA Netw Open 2018;1:e180281.

30. Deonandan R, Khan H. Ethics education for pediatric residents: a review of the literature. Can Med Educ J 2015;6:e61-7.

31. Pageler NM, Friedman CP, Longhurst CA. Refocusing medical education in the EMR era. JAMA 2013;310:2249-50.

32. GBD 2016 DALYs and HALE Collaborators. Global, regional, and national disability-adjusted life-years (DALYs) for 333 diseases and injuries and healthy life expectancy (HALE) for 195 countries and territories, 1990-2016: a systematic analysis for the Global Burden of Disease Study 2016. Lancet 2017;390:1260-344.

33. Jogerst $\mathrm{K}$, Callender B, Adams V, et al. Identifying interprofessional global health competencies for 21st-century health professionals. Ann Glob Health 2015;81:239-47.

34. Arya N, Dahlman B, Gibson C, et al. Developing family practice to respond to global health challenges: the Besrour papers: a series on the state of family medicine in the world. Can Fam Physician 2017;63:602-6.

35. Wroe EB, McBain RK, Michaelis A, et al. A novel scenario-based interview tool to evaluate nontechnical skills and competencies in global health delivery. J Grad Med Educ 2017;9:467-72.

36. Dawe R, Pike A, Kidd M, et al. Enhanced skills in global health and health equity: guidelines for curriculum development. Can Med Educ J 2017;8:e48-60.

37. Casanova Dias M, Abbara A, Gilbert R, et al. Equipping doctors for global health challenges. J R Soc Med 2017;110:5-8.

38. Tupesis JP, Jacquet GA, Hilbert S, et al. The role of graduate medical education in global health: proceedings from the 2013 Academic Emergency Medicine consensus conference. Acad Emerg Med 2013;20:1216-23.

39. Bjorklund AB, Cook BA, Hendel-Paterson BR, et al. Impact of global health residency training on medical knowledge of immigrant health. Am J Trop Med Hyg 2011;85:405-8. 